\title{
Improving the performance of hysteresis direct torque control of IPMSM using active filter topology
}

\author{
KAYHAN GULEZ, ALI AHMED ADAM and HALIT PASTACI \\ Yildiz Technical University, Electrical-Electronic Faculty, Electrical Engineering \\ Department, 34349 Besiktas-Istanbul, Turkey \\ e-mail: \{gulez,hpastaci@yildiz.edu.tr; aliadam999@yahoo.com\}
}

MS received 31 March 2004; revised 30 January 2006

\begin{abstract}
This paper describes an active filter topology to improve the performance of hysteresis direct torque control (HDTC) of interior permanent magnet synchronous motor (IPMSM). The filter topology consists of an active filter and two RLC filters, and is connected to the main power circuit through a 1:1 transformer. The active filter is characterized by detecting the harmonics in the motor phase voltages and injecting equivalent harmonic voltages to produce almost sinusoidal voltage waveform to the motor terminals. The active filter uses hysteresis voltage controller while the motor main circuit uses hysteresis direct torque control. The simulation results of this combined control structure show considerable torque ripple reduction in the steady state range and adequate dynamic torque performance as well as considerable harmonic voltage and EMI noise reduction.
\end{abstract}

Keywords. Interior permanent magnet synchronous motor; direct torque control; stator flux linkage; active power filter; voltage harmonics; torque ripples.

\section{Introduction}

Hysteresis direct torque control (HDTC) of an interior permanent magnet synchronous motor (IPMSM) involves direct control of stator flux linkages and generated electromagnetic torque by applying optimum voltage-switching vectors to the inverter supplying the motor. Although HDTC when compared to rotor field oriented control has many advantages such as elimination of the $d-q$ axis current controllers, elimination of rotor position required for transformation and fast torque response (Zhong et al 1997), it has many disadvantages such as large switching harmonics and voltage harmonics supplied by the power inverter which constitute the major source of harmonics in IPMSM. These harmonics cause many undesired phenomena such as electromagnetic interference (EMI) and torque ripples that result in speed oscillations, mechanical vibration and acoustic noise, which reduce the performance of the drive in demanding applications (Holtz \& Springob 1996). These drawbacks are especially high when the sampling period is greater than $40 \mu$ s (Zhong et al 1997).

Figure 1 shows the basic structure of HDTC of IPMSM with switching (table 1) (Vas 1998; Dan et al 2000; Luukko 2000). In figure 1, the switching of the inverter is updated only once 


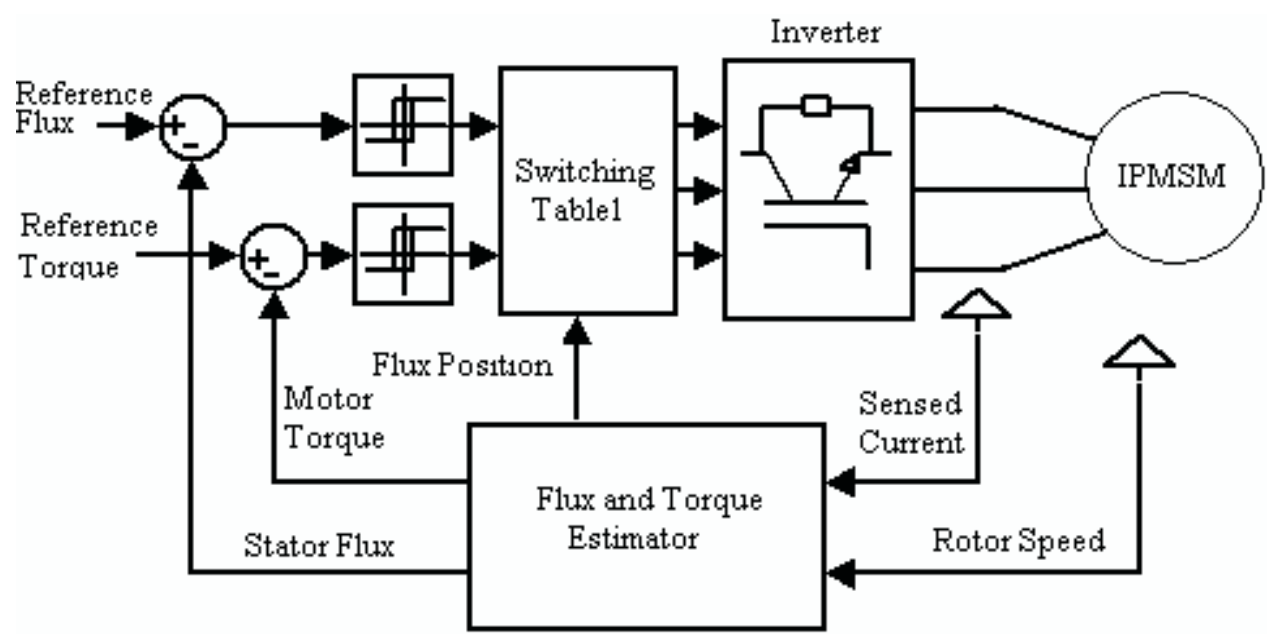

Figure 1. The basic structure of HDTC for IPMSM.

when the outputs of the hysteresis controllers change states, which result in variable switching frequency, and the associated large harmonic range and high current ripples, which affect the passive filter and hamper its proper design.

Recently, many research efforts have been carried out to reduce the torque ripples and harmonics in PMSM with varying degrees of success, Holtz \& Springob (1996) and Springob \& Holtz (1998) successively investigated the different sources of torque ripple in permanent magnet machines and explained that torque pulsations are generated by distortion of the stator flux linkage distribution. From the stator slotting effects, unbalanced magnetization, and secondary phenomena, they defined models based on a complex state variable approach for the ripple generating mechanisms and presented a concept for the compensation of torque ripple by a self-commissioning and adaptive control system, where a deadbeat current controller and a current predictor were used. The effectiveness of their adaptive torque ripple compensation was demonstrated by experimental results, where they achieved accurate deadbeat current response, and improved the quality of the current waveforms. Luukko (2000) has improved the switching table by inserting the zero vectors (i.e. $V_{0}$ and $V_{7}$ ) in vector selection algorithm but however, no significant change in torque ripples and harmonics level have been observed. Tan et al (2001) and Martins et al (2002) have used multilevel inverters to reduce torque ripples and fixing switching frequency in AC drive systems, though it presents advantages such as smoother waveform, less distortion and lower switching frequency over the conventional inverters, it requires larger amount of switching elements, in addition the control strategy of these topologies is very complicated. Tang et al (2004) and Chung et al (1998) have used effectively space vector modulation to reduce torque and flux ripples in PMSM.

Many other researchers used filter topologies to improve waveform in PMSM. Sozer et al (2000) have presented an inverter output filter topology for PWM motor drives to reduce harmonics of PMSM, their proposed filter is composed of conventional RLC filter cascaded with an LC trap filter, the scheme shows some effectiveness in reducing switching harmonics, but however the voltage harmonics are still high and the trap filter used requires tuning to adjust for switching frequency variation. Harrori et al (2001) and Kim et al (2002) have proposed a suppression control method of the motor frame vibration and the rotational speed vibration of PMSM utilizing feed-forward compensation control to suppress the harmonic 


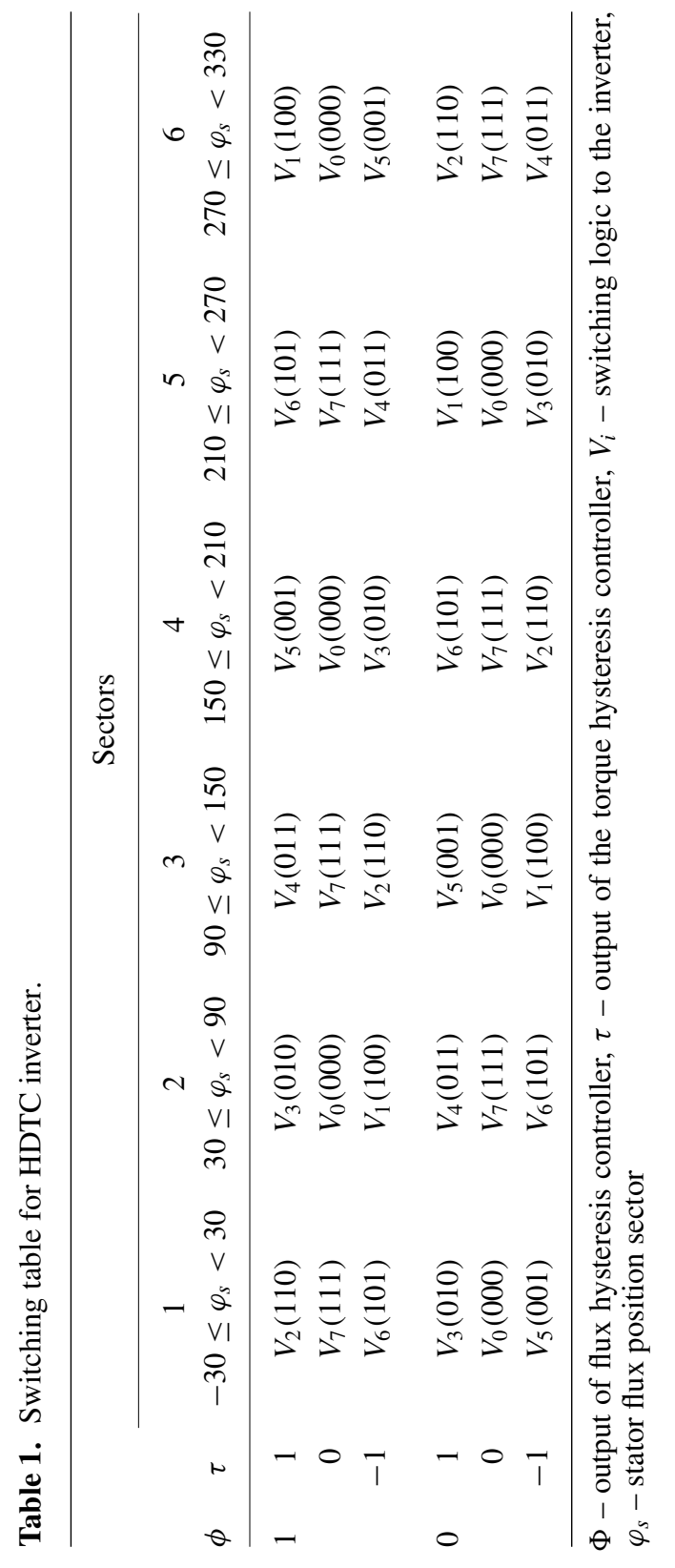


contents in the $d-q$ control signals by repetitive control and Fourier transform. However, their work has nothing to do with switching or voltage harmonics provided by the PWM inverter supplying the motor.

In this study, a new filter topology is proposed to reduce torque ripples and voltage harmonic noises in IPMSM with direct torque hysteresis controllers. The filter topology consists of a series active filter (AF) and two RLC filters, one on the primary side and the other on the secondary side of a coupling transformer. The AF is characterized by detecting the harmonics in the motor phase voltages and uses hysteresis voltage control to provide almost sinusoidal voltage to the motor windings.

\section{The proposed system configuration}

Series active power filters were introduced by the end of the 1980s and operate mainly as a voltage regulator and as a harmonic isolator between the nonlinear load and the utility system (Rudnik et al 2003). Since series active power filters inject a voltage component in series with the supply voltage, they can be regarded as a controlled voltage source. Thus this type of filter is adopted here to compensate the harmonic voltages from the inverter supplying the motor.

Figure 2 shows a block diagram of the proposed system. The motor control block is hysteresis direct torque control as the one shown in figure 1 with switching (table 1).

The active filter storage capacitor $C_{F}$ which operates as a voltage source should be carefully selected to hold up to the motor line voltage. The smoothing inductance $L_{F}$ should be large enough to obtain almost sinusoidal voltage at the motor terminals.

The IPMSM equations in rotor reference frame are given as:

$$
\begin{aligned}
{\left[\begin{array}{c}
v_{s d} \\
v_{s q}
\end{array}\right] } & =\left[\begin{array}{cc}
R+p L_{s d} & -P \omega_{r} L_{s q} \\
P \omega_{r} L_{s d} & R+p L_{s q}
\end{array}\right]\left[\begin{array}{c}
i_{s d} \\
i_{s q}
\end{array}\right]+\left[\begin{array}{c}
0 \\
e_{B}
\end{array}\right], \\
T_{e} & \left.=(3 / 2) P\left(\psi_{F} i_{s q}+\left(L_{s d}-L_{s q}\right) i_{s d} i_{s q}\right)\right),
\end{aligned}
$$

where,

$v_{s d}, v_{s q}-d$-axis and $q$-axis stator voltages,

$i_{s d}, i_{s q}-d$-axis and $q$-axis stator currents,

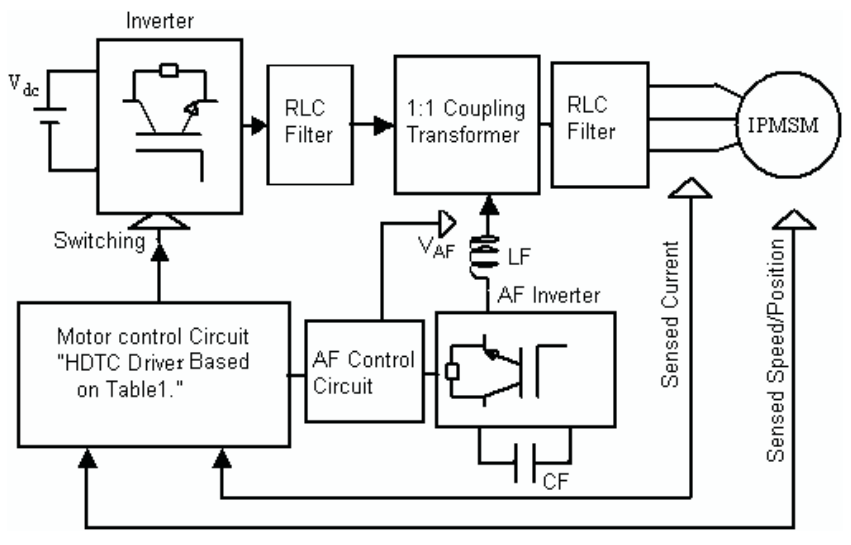

Figure 2. Block diagram of the proposed filter topology. 
$R$ - stator winding leakage resistance,

$L_{s d}, L_{s q}-d$-axis and $q$-axis stator inductances,

$p=\mathrm{d} / \mathrm{d} t-$ differential operator,

$P$ - number of pole pairs of the motor,

$\omega_{r}$ - rotor speed,

$\Psi_{F}$ - rotor permanent magnetic flux,

$e_{B}=P \omega_{r} \Psi_{F}-$ is the generated back emf due to $\Psi_{F}$,

$T e$ - generated electromagnetic torque.

The proposed filter topology consists of three parts, one is the filter control circuit, the other is the active filter power circuit, and the third is the transformer-RLC coupling part. In the following sections, these parts are explained.

\subsection{Active filter control circuit}

The effectiveness of the active filter is mainly defined by the algorithm used to control the switching signal of AF. These signals must allow voltage compensation with minimum time delay. In this study, the method used to generate the voltage reference signals is related to the control algorithm of the motor, which uses the motor model in rotor $d-q$ reference frame and rotor field-oriented control principles with monitored rotor position/speed and monitored phase currents.

Figure 3 shows the AF control circuit. In this circuit, the required active filter switching signals are generated by comparing generated reference signal $V^{*}$ with the main inverter measured output voltage. The comparison result $V_{\text {sig }}$ is the desired voltage to be injected in order to obtain sinusoidal voltage at the motor terminals. This required voltage is compared with the actual output voltage of the active filter $V_{\mathrm{AF}}$ and the resulted error is passed to hysteresis controller to arrange the switching of the active filter in such a way as to have the motor phase voltages approach sinusoidal waveform.

The reference sinusoidal voltage $V^{*}$ which should be in phase with the main inverter output voltage, is generated from the motor model in steady state (can also be calculated

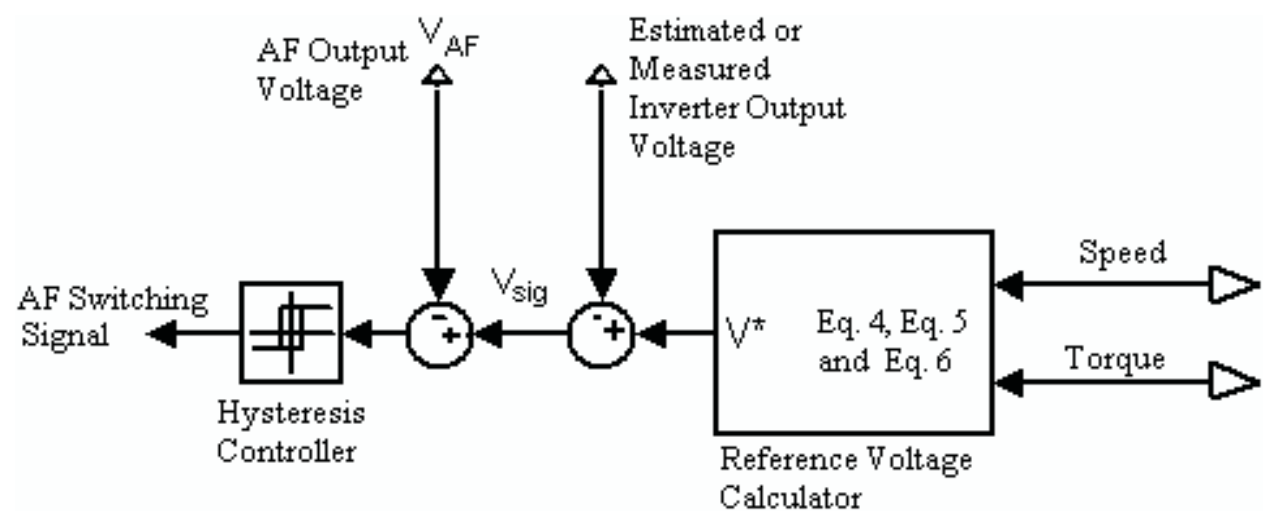

Figure 3. The proposed AF control circuit. 
in the transient state from the same equations). The motor model, in synchronously rotating reference frame shown in (1), can be rewritten in the steady state as:

$$
\left[\begin{array}{c}
V_{s d} \\
V_{s q}
\end{array}\right]=\left[\begin{array}{cc}
R & -X_{s q} \\
X_{s d} & R
\end{array}\right]\left[\begin{array}{c}
I_{s d} \\
I_{s q}
\end{array}\right]+\left[\begin{array}{c}
0 \\
e_{B}
\end{array}\right],
$$

where, $X_{s d}$ and $X_{s q}$ are $d$ and $q$ axis reactances.

Under the base speed operation, speed control can be achieved by forcing the stator current component $i_{s d}$ to be zero while controlling the $i_{s q}$ component to be directly proportional to the motor torque $T_{e}$ as in,

$$
T_{e}=(3 / 2) P \psi_{F} i_{s q} .
$$

Therefore, given the reference torque value, the steady state $q$-axis current can be extracted from (4) and hence the steady state $d$ - and $q$-axis voltages can be calculated as:

$$
\begin{aligned}
& V_{s d}=-X_{s q} I_{s q}, \\
& V_{s q}=R I_{s q}+P \omega_{r} \psi_{F} .
\end{aligned}
$$

Once the values of $d$-axis and $q$-axis voltage components are obtained, Park / Clarke transformation can be used to obtain the reference sinusoidal voltages as:

$$
\left[\begin{array}{c}
v_{a}^{*} \\
v_{b}^{*} \\
v_{c}^{*}
\end{array}\right]=K\left[\begin{array}{cc}
1 & 0 \\
-1 / 2 & \sqrt{3} / 2 \\
-1 / 2 & -\sqrt{3} / 2
\end{array}\right]\left[\begin{array}{cc}
\cos \theta & -\sin \theta \\
\sin \theta & \cos \theta
\end{array}\right]\left[\begin{array}{c}
V_{s d} \\
V_{s q}
\end{array}\right],
$$

where, $K$ is the transformation constant and $\theta$ is rotor position.

\subsection{Active filter power circuit}

Figure 4 shows simplified per-phase equivalent power circuit of the proposed filter topology (the passive RLC filters are not shown).

In this circuit, $V_{\text {inv }}$ is the voltage of the main inverter circuit, $V_{C F}^{+}$and $V_{C F}^{-}$are equivalent compensated voltage sources of the active filter. In order to generate the required compensation

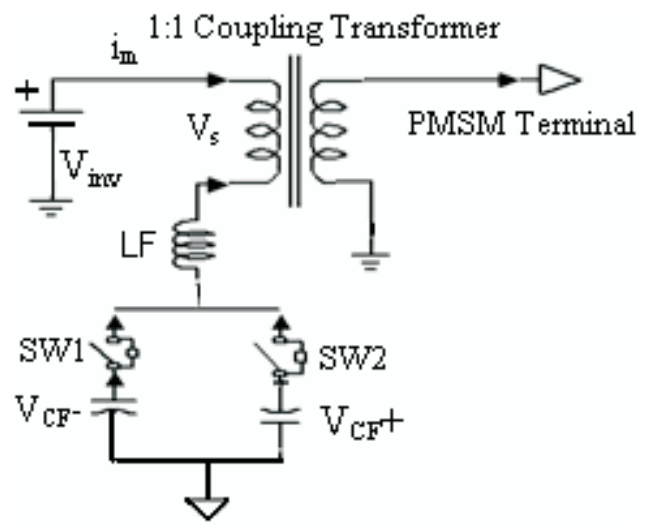

Figure 4. Simplified per-phase equivalent power circuit of the proposed filter topology (the RLC filters are not shown). 


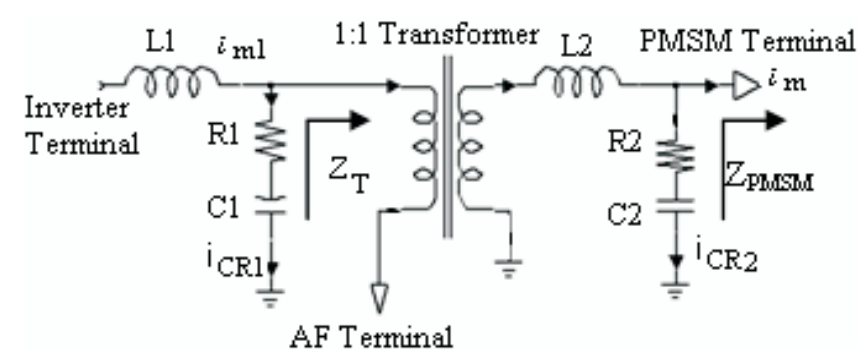

Figure 5. Coupling circuit between $\mathrm{AF}$ and main inverter on one side and IPMSM on the other.

voltages that follow the voltage signal $v_{\text {sig }}$, the switches $\mathrm{SW}_{1}$ and $\mathrm{SW}_{2}$ are controlled to keep the motor winding voltages within the acceptable hysteresis band. The motor line current $i_{m}$ is controlled within the motor main control circuit with hysteresis controllers to provide the required load torque; therefore, two hysteresis controller systems, one for voltage and the other for current are working independently to supply the motor with almost sinusoidal voltage. This voltage can be estimated as:

$$
V_{s}=V_{\mathrm{inv}}+V_{C F}^{ \pm}+L_{F}\left(\mathrm{~d} i_{m} / \mathrm{d} t\right) .
$$

\subsection{The coupling}

The coupling between the main inverter circuit and the active filter circuit is achieved through 1:1 transformer, and to attenuate the higher frequency EMI noises, RLC filters are used at the transformer primary and secondary windings as suggested by figure 5 .

The important point here is that, the resonance which may arise between capacitor $C_{1}$ and transformer primary winding and between capacitor $C_{2}$ and motor inductance winding should be avoided when selecting capacitor values. At selected cut-off frequency, the currents $i_{C R 1}$ and $i_{C R 2}$ derived by the RLC filters are given by

$$
\begin{aligned}
& i_{C R 1}=\left(z_{T}\right) /\left[z_{T}+\left(R_{1}+1 / s C_{1}\right)^{1 / 2}\right] i_{m 1} \quad \text { and } \\
& i_{C R 2}=\left(z_{P M S M}\right) /\left[z_{P M S M}+\left(R_{2}+1 / s C_{2}\right)^{1 / 2}\right] i_{m 2},
\end{aligned}
$$

where, $Z_{T}$ and $Z_{P M S M}$ are as defined in figure 5 .

At selected cut-off frequency, these currents should be large compared to $i_{m 1}$, drawn by the transformer, and/or $i_{m}$, drawn by the motor, while at operating frequency these currents should be very small compared with $i_{m 1}$ and $i_{m}$. Another point in selection of the RLC parameters is that the filter inductors are essentially shorted at line frequency, while the capacitors are open circuit and for EMI noise frequencies, the inductors are essentially open circuit, while the capacitors are essentially shorted. Thus, considerable amount of EMI noise will pass through the filter resistors to the earth and cause frequency dependent voltage drop across the inductors which, in turn, help in smoothing of the voltage waveform supplying the motor.

\section{Simulations and results}

In order to verify that the proposed filter topology does actually improve the performance of the conventional HDTC methods, the well-known HDTC shown in figure 1 is implemented 
Table 2. IPMSM parameters.

\begin{tabular}{lcl}
\hline Number of pole pairs & $P$ & 2 \\
Stator winding resistance & $R_{s}$ & $5.8 \mathrm{ohm}$ \\
$q$-axis inductance & $L_{s q}$ & $102.7 \mathrm{mH}$ \\
$d$-axis inductance & $L_{s d}$ & $44.8 \mathrm{mH}$ \\
Permanent magnet flux & $\Psi_{F}$ & $533 \mathrm{mWb}$ \\
Inertia constant & $J$ & $0.000329 \mathrm{Nms}^{2}$ \\
Friction constant & $B$ & 0.0 \\
Reference speed & $\omega$ & $70 \mathrm{rad} / \mathrm{s}$ \\
Load torque & $T_{L}$ & $2 \mathrm{Nm}$ \\
\hline
\end{tabular}

in Matlab/Simulink to compare the performance of the IPMSM, with and without the filter topology under the same operating and loading conditions.

The IPMSM is star-connected with earth return. The motor parameters are shown in table 2, while the passive filters parameters are shown in table 3. The AF capacitor used is $200 \mu \mathrm{F}$ and its inductors are $200 \mathrm{mH}$.

Simulation results with $100 \mu$ s sampling time and $\pm 0 \cdot 1 \mathrm{Nm}$ hysteresis torque band are shown in figures 6-14. The torque dynamic response is simulated with open speed loop, while steady state performance is simulated with closed speed loop at $70 \mathrm{rad} / \mathrm{s}$ as reference speed, and $2 \mathrm{Nm}$ as load torque.

\subsection{Torque dynamic response}

The torque dynamic responses before and after connecting the $\mathrm{AF}$ are shown in figures $6 \mathrm{a}$ and $\mathrm{b}$ respectively. The reference torque for both figures is changed from $+2 \cdot 0$ to $-2 \cdot 0$ and then to $3.0 \mathrm{Nm}$. As shown in the figures, the dynamic response with the proposed filter topology adequately follows the reference torque with lower torque ripples and settles down within $\pm 0 \cdot 1 \mathrm{Nm}$ band of the reference torque; while the torque dynamic under HDTC without filter topology cannot settle down thus due to the presence of high torque ripples $( \pm 1.0 \mathrm{Nm})$. On the other hand, the torque response time without filter topology is shorter $(\sim 1.2 \mathrm{~ms})$ than the torque response time with the proposed filter topology $(2.5 \mathrm{~ms})$. This delay in the torque response with the proposed filter topology is mainly due to delay of current propagation through the $L_{F} C_{F}$ loop of the active filter; however this is not significant if compared with the results provided by Tang et al (2004).

\subsection{Motor steady state performance}

Motor performance before and after applying the AF are shown in figures 7-10. Figure 7 shows the phase voltage provided to the motor terminals before and after applying the filter topology. Observing change of the waveform after applying the AF, we see that the phase

Table 3. RLC-filter parameters.

\begin{tabular}{llll}
\hline$L_{1}$ & $15 \mu \mathrm{H}$ & $L_{2}$ & $15 \mu \mathrm{H}$ \\
$C_{1}$ & $2 \mu \mathrm{F}$ & $C_{2}$ & $2 \mu \mathrm{F}$ \\
$R_{1}$ & $250 \Omega$ & $R_{2}$ & $750 \Omega$ \\
\hline
\end{tabular}



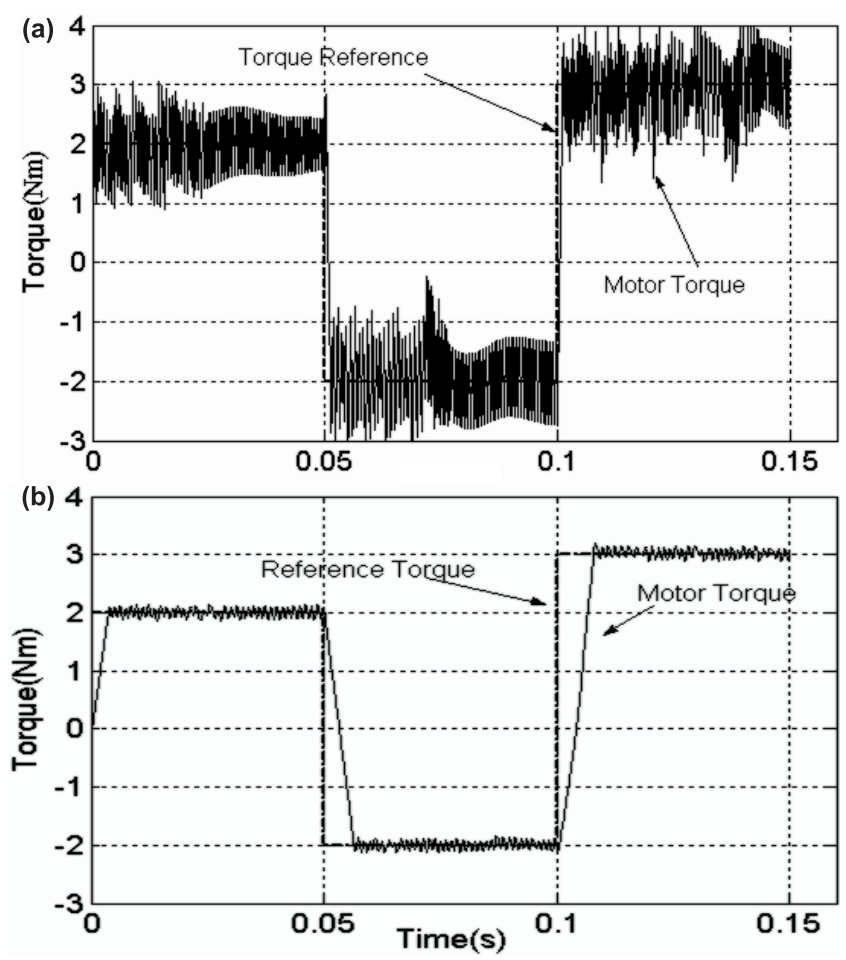

Figure 6. Motor torque dynamic response under basic HDTC (a) without and (b) after connecting the AF topology.
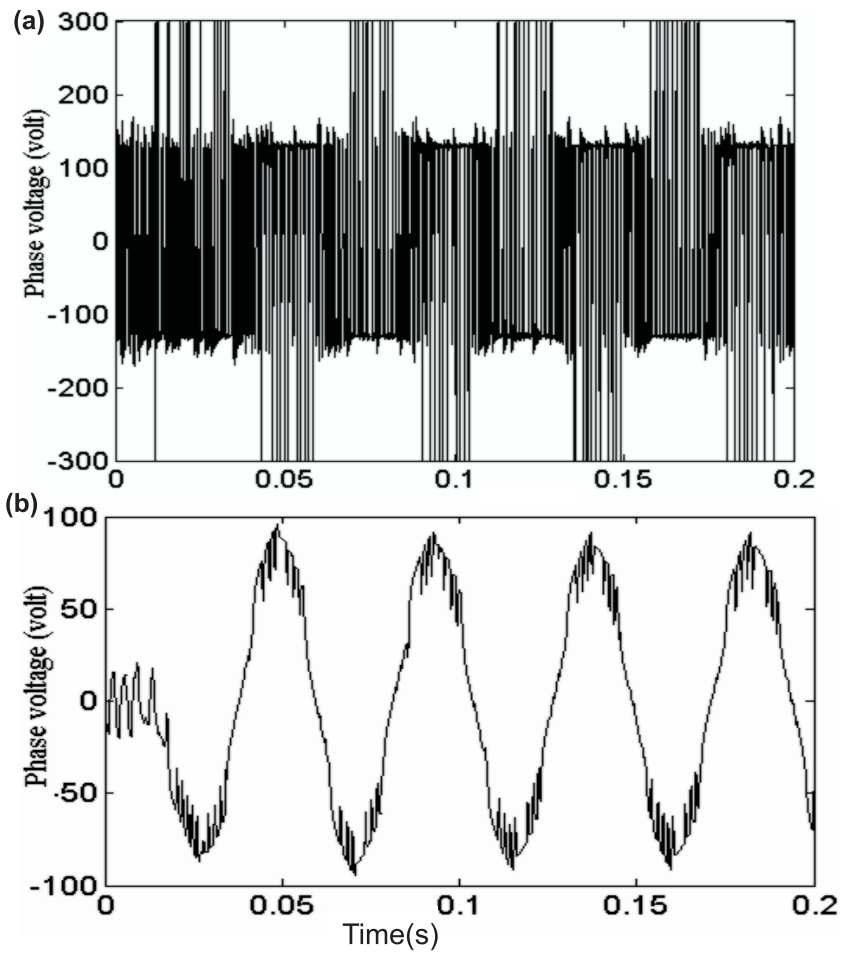

Figure 7. Starting motor phase voltage under basic HDTC (a) before and (b) after connecting AF topology. 
voltage approaches sinusoidal waveform almost free of voltage pulses (figure $7 \mathrm{a}$ ) due to inverter switching. Better waveform can be obtained by increasing the active filter inductance $L_{F}$, however, the cost and size of the AF increases, and therefore suitable inductance value can be selected to achieve acceptable performance. Similar results have been provided by Sozer et al (2000); however, as compared to the above result, their sinusoidal voltage waveform supplied to the motor terminals is full of harmonic components.

Figure 8 shows the response of the motor line currents under HDTC without and with the proposed filter topology. In figure 8a, high distortion in line current can be observed; however the current waveform is smoother after applying the proposed filter topology. The reason for the high current distortion (ripples) is mainly due to the fact that switching of the inverter is only updated once at the sampling instances when the hysteresis controllers change state, and hence, in the presence of the proposed active filter, a proper voltage is provided to the motor terminal, which in turn decreases current ripples.

The torque response in figure 9 shows considerable reduction in torque ripples around the load torque when the proposed active filter is connected. The higher ripples of $\pm 1.62 \mathrm{Nm}$ around the load torque in figure $9 \mathrm{a}$ are mainly due to the existence of harmonic voltages provided to the motor terminals, so when the harmonics are reduced after insertion of the proposed filter topology the torque ripples are decreased down to $\pm 0 \cdot 1 \mathrm{Nm}$ as shown in figure $9 \mathrm{~b}$. The reduction in the torque ripples is normally reflected in reduced motor mechanical vibration and hence reduced acoustic noise as well as smoother speed response as shown in figure 10 .
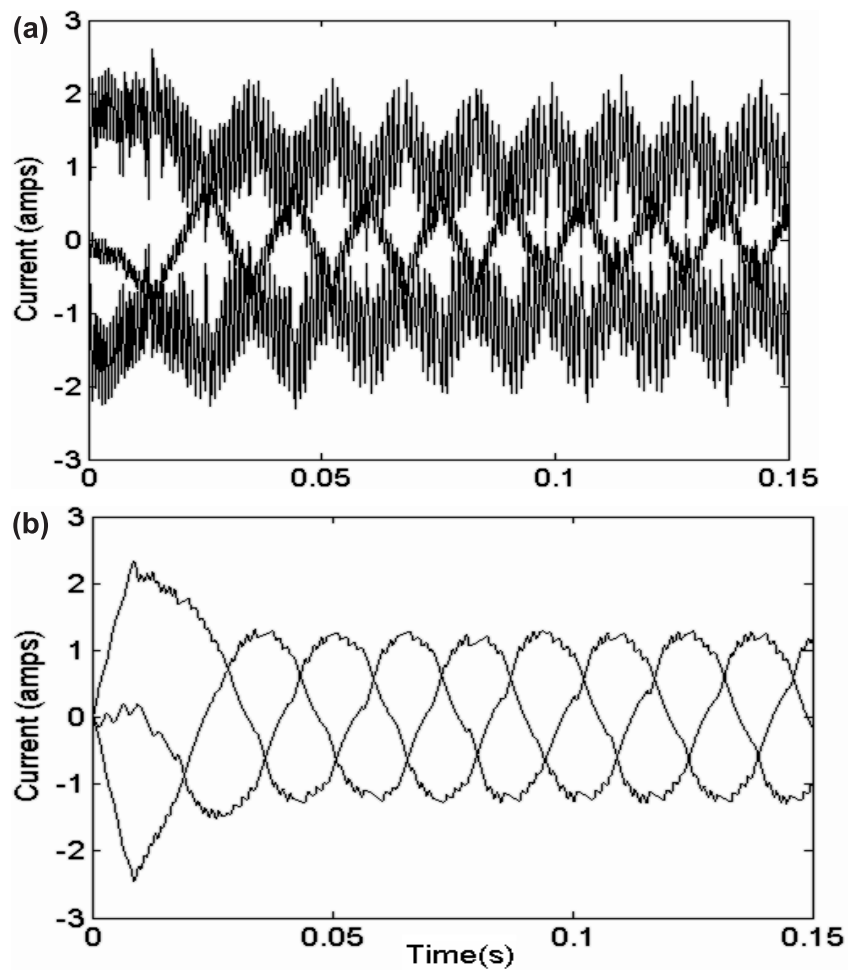

Figure 8. Motor line currents responses under basic HDTC before (a) and after (b) applying AF topology. 

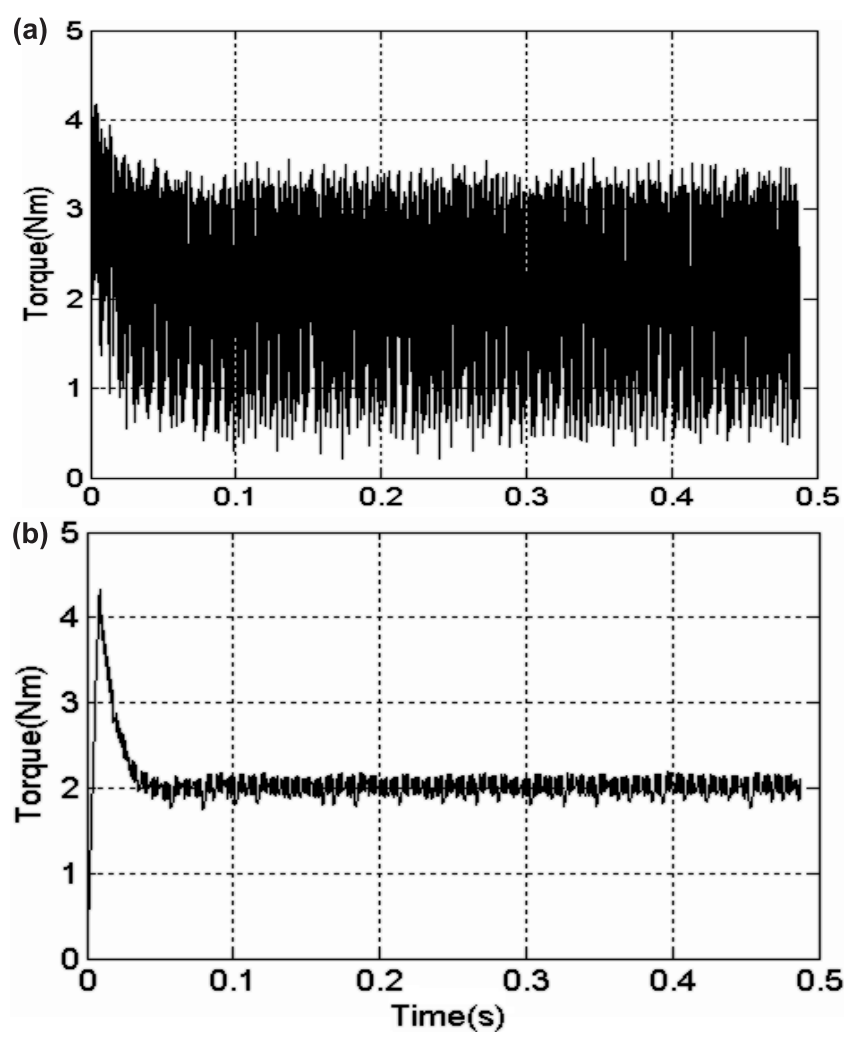

Figure 9. Steady state motor torque response under basic HDTC before (a) and after (b) connecting the AF topology (load torque $=2 \cdot 0 \mathrm{Nm})$.

\subsection{Harmonics and EMI noise reduction}

The phase voltage harmonics and EMI noise in the line currents before and after connecting the AF are shown in figures 11-14.

In figure 11 the spectrum of the phase voltage before connecting the AF shows that the harmonic voltages with THD of $\sim 79 \%$ are widely scattered in the frequency range shown. These harmonic voltages, if not cleared or reduced, result in parasitic ripples in motor-developed torque and contribute to electromagnetic interference noise. However, after connecting the $\mathrm{AF}$, the THD is effectively reduced to less than $5 \%$ as shown in figure 12 .

The EMI noise level before connecting the $\mathrm{AF}$ in figure 13 shows a noise level of $\sim 20 \mathrm{~dB}$ at operating frequency, $\sim 18 \mathrm{~dB}$ at switching frequency $(5 \mathrm{kHz})$, and almost $-40 \mathrm{dBs}$ for higher frequencies $(>0 \cdot 2 \mathrm{MHz})$. These noise component frequencies have bad effects on the control system if not filtered out. When the AF is connected, EMI noise level is tuned down to $\sim-18 \mathrm{~dB}$ at operating frequency, $\sim-25 \mathrm{~dB}$ at switching frequency and less than $\sim-60 \mathrm{dBs}$ for the most high frequencies as shown in figure 14 .

From the results presented it can be seen that the steady state performance of the HDTC with the proposed filter topology is much better than the performance presented by Zhong (1997). This result can also be compared with the experimental results reported by Tang et al (2004) though the effective average switching sampling time in that method is much less than the selected sampling period $(150 \mu \mathrm{s})$. Due to this fact the space vector modulation is used to drive the inverter. 

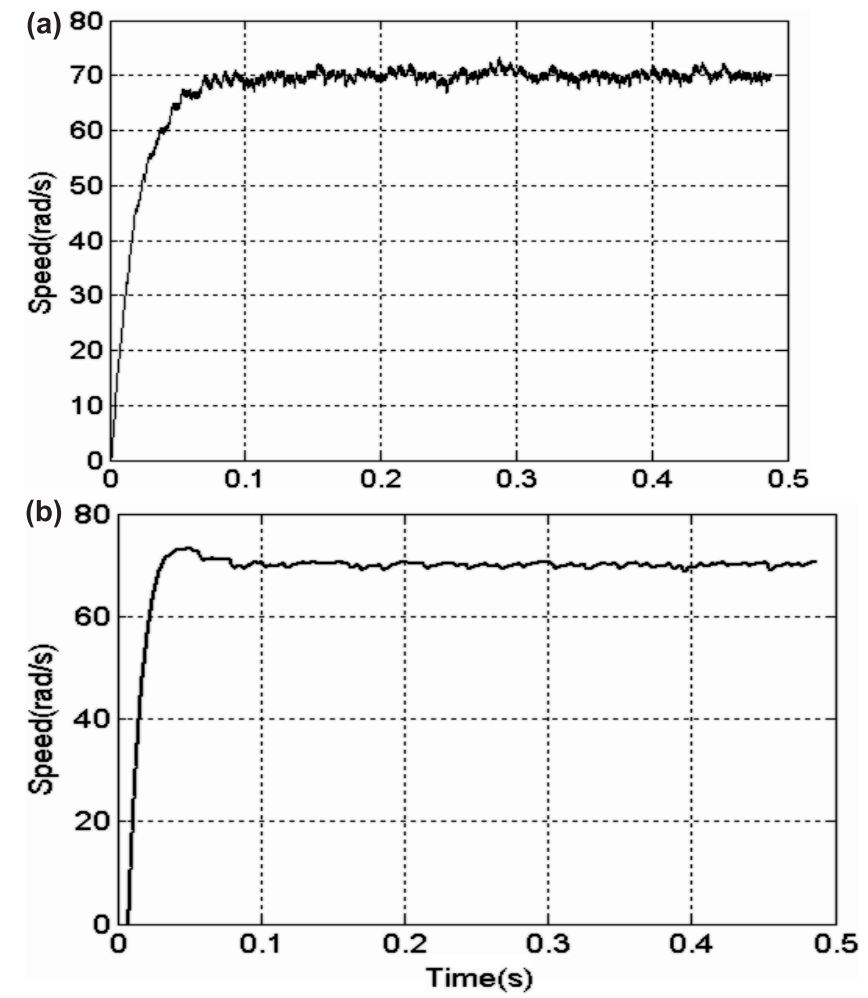

Figure 10. Rotor speed under basic HDTC before (a) and after (b) applying the AF topology $\left(\right.$ reference speed $\omega_{0}=70 \mathrm{rad} / \mathrm{s}$ ).
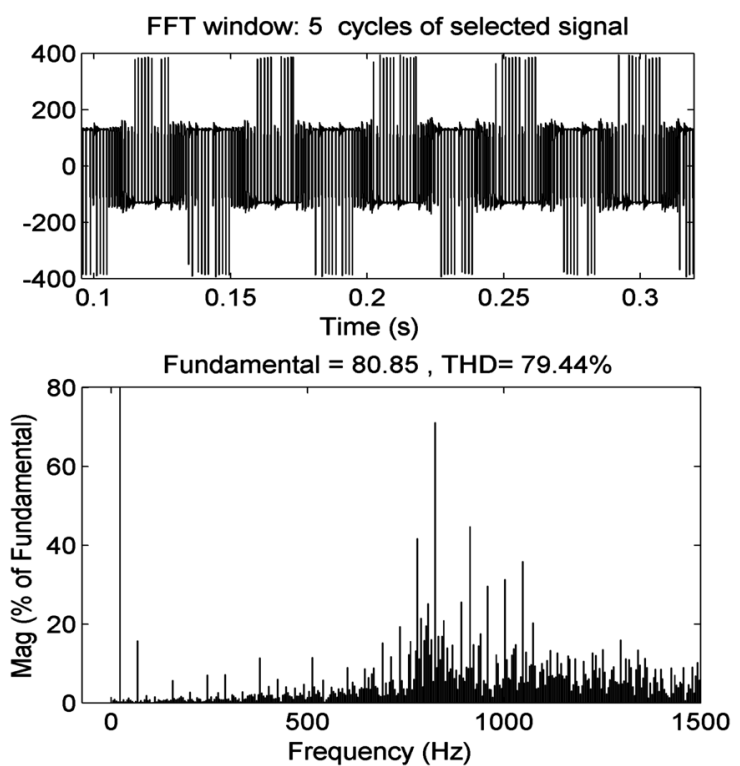

Figure 11. Phase-a voltage (top) and its spectrum (bottom), before connecting the AF topology. 

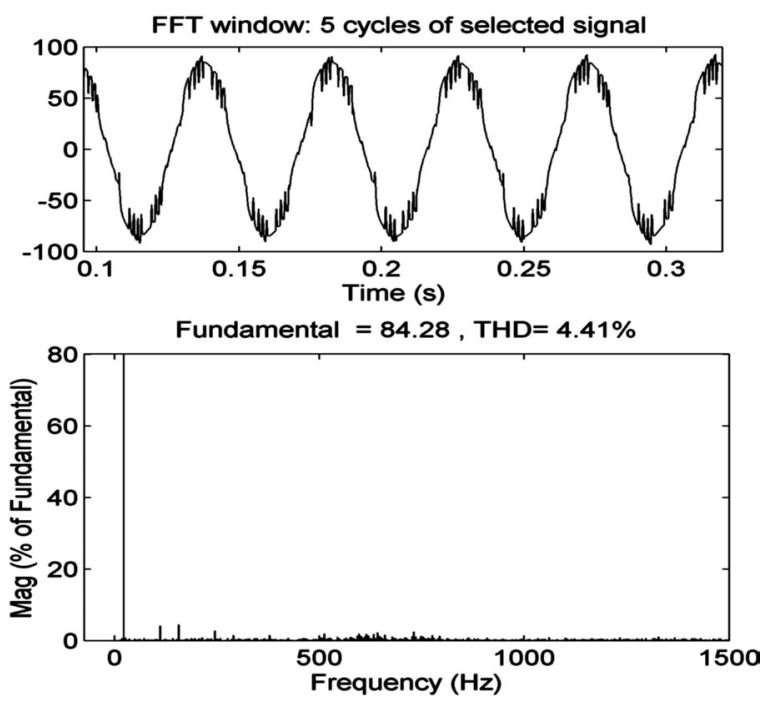

Figure 12. Phase-a voltage (top) and its spectrum (bottom), after connecting the AF topology.
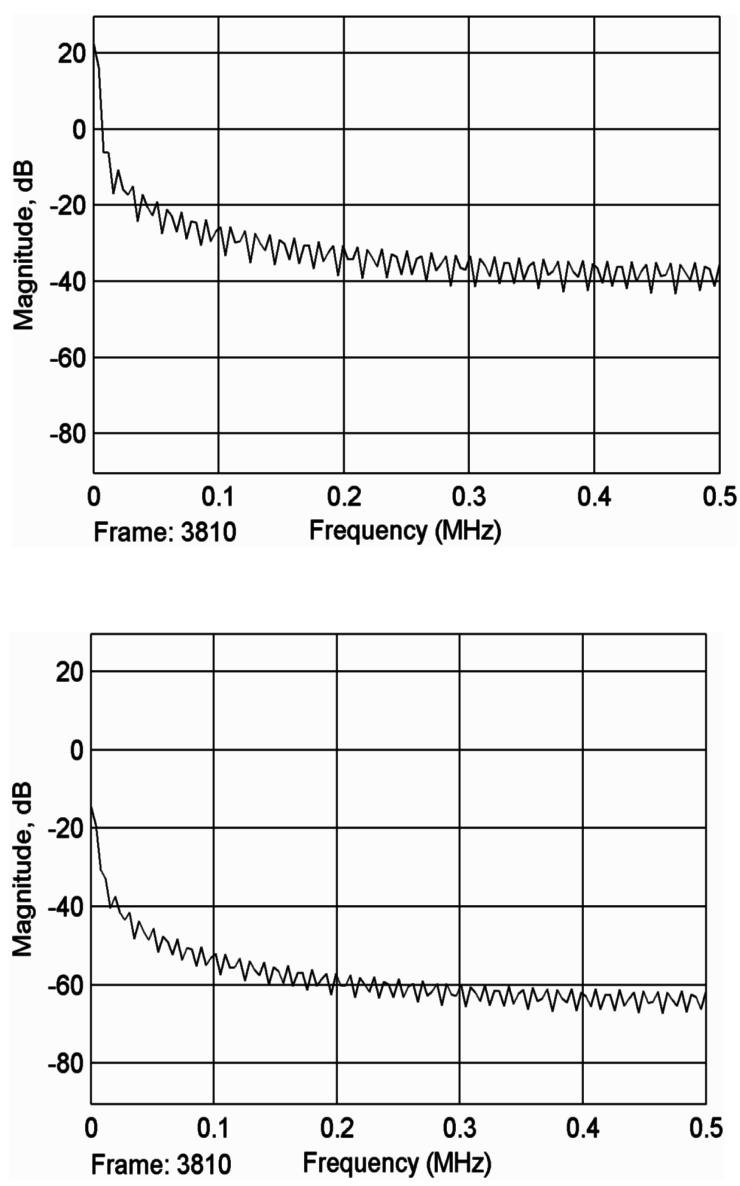

Figure 13. EMI noise level before connecting the $\mathrm{AF}$.

Figure 14. EMI noise level after connecting the AF. 
The motor voltage waveform is better than that provided by Sozer et al (2000), besides which the filter topology presented by them requires continuous tuning when the switching frequency is changed. In addition, in order to obtain acceptable sinusoidal waveforms, the resistor value used in the RLC loop is small, which involves larger currents flowing through the loop composed of the RLC and the inverter, and which in turn causes overloading at the inverter elements.

\section{Conclusions}

In this paper, a new AF topology for HDTC was presented and simulated. The filter topology combines the compensation characteristics of series AF and L type passive EMI filters. It was shown that the proposed topology is capable of reducing torque ripples which exist in HDTC as well as reducing the harmonics and EMI noise in phase voltages and currents, as reflected in almost sinusoidal voltage to the motor terminals.

\section{References}

Chung S-K, Kim H-S, Youn M-J 1998 A new instantaneous torque control of PM synchronous motor for high-performance direct-drive applications. IEEE Trans. Power Electron. 13: 388-400

Dan S, Weizhong F, Yikang H 2000 Study on the direct torque control of permanent magnet synchronous motor drives. Proc. Fifth Int. Conf. on Electrical Machines and Systems, Shenyang, China, 1: $571-574$

Harrori S, Ishida M, Hori T 2001 Vibration suppression control method for PMSM utilizing repetitive control with auto-tuning function and fourier transform. IECON'01: The 27th Annu. Conf. of IEEE Industrial Electronics Society, pp 1673-1679

Holtz J, Springob L 1996 Identification and compensation of torque ripple in high-precision permanent magnet motor drives. IEEE Trans. Ind. Electron. 43: 309-320

Kim J-S, Doki S, Ishida M 2002 Improvement of IPMSM sensor less control performance using Fourier transform and repetitive control. IECON'02: The 28th Annu. Conf. of IEEE Industrial Electronics Society, pp 597-602

Luukko J 2000 Direct torque control of permanent magnet synchronous machines - Analysis and implementation. Dissertation Lappeenranta University of Technology, Lappeenranta, Stockholm

Martins C, Roboam X, Meynard T A, Carylho A S 2002 Switching frequency imposition and ripple reduction in DTC drives by a multilevel converter. IEEE Trans. Power Electron. 17: 286-297

Rudnick H, Dixon J, Morán L 2003 Active power filters as a solution to power quality problems in distribution networks. IEEE Power Energy Mag. : 32-40

Springob L, Holtz J 1998 High-bandwidth current control for torque-ripple compensation in PM synchronous machines. IEEE Trans. Ind. Electron. 45: 713-721

Sozer Y, Torrey D A, Reva S 2000 New inverter output filter topology for PWM motor drives. IEEE Trans. Power Electron. 15: 1007-1017

Tan Z, Li Y, Li M 2001 A direct torque control of induction motor based on three level inverter. IEEE, PESC'2000 2: 1435-1439

Tang L, Zhong L, Rahman M F, Hu Y 2004 A novel direct torque controlled interior permanent magnet synchronous machines drive with low ripple in flux and torque and fixed switching frequency. IEEE Trans. Power Electron. 19:

Vas P 1998 Sensor less vector and direct torque control (New York: Oxford University Press)

Zhong L, Rahman M F, Hu W Y, Lim K W 1997 Analysis of direct torque control in permanent magnet synchronous motor drives. IEEE Trans. Power Electron, 12: 528-536 